\title{
Optimization of Drying Process for Squid-Laver Snack by a Combined Method of Fuzzy Synthetic and Response Surface Methodology
}

\author{
Chang-Cheng Zhao, Gui-Hun Jiang, and Jong-Bang Eun \\ Department of Food Science and Technology and BK 21 Plus Program, Graduate School of Chonnam National University, \\ Gwangju 61186, Republic of Korea
}

Correspondence should be addressed to Jong-Bang Eun; jbeun@jnu.ac.kr

Received 28 September 2017; Accepted 4 December 2017; Published 19 December 2017

Academic Editor: Giuseppe Zeppa

Copyright (c) 2017 Chang-Cheng Zhao et al. This is an open access article distributed under the Creative Commons Attribution License, which permits unrestricted use, distribution, and reproduction in any medium, provided the original work is properly cited.

\begin{abstract}
The aim of this study was to investigate the effects of drying temperature $\left(50-70^{\circ} \mathrm{C}\right)$ and drying time $(3-5 \mathrm{~h})$ on the physical properties and quality of squid-laver snack (SLS) using response surface methodology combined with a synthetic evaluation method to optimize the drying process conditions. Moisture content, water activity, color $\left(L^{*}, a^{*}, b^{*}\right)$, shear force, and overall acceptability were evaluated as responses. Increased drying times and higher temperatures significantly reduced the moisture content and water activity of SLS from $9.07 \%$ to $4.76 \%$ and 0.136 to 0.056 , respectively $(p<0.05)$. There was no significant difference in the $L^{*}$ and $a^{*}$ values under different drying conditions. The quadratic effect of temperature and time was observed for the $b^{*}$ value and overall acceptability of SLS. For shear force, a quadratic and interaction term for drying temperature and time on shear force was observed. In conclusion, the recommended optimal hot air-drying conditions for SLS are temperature and time of $70^{\circ} \mathrm{C}$ and $3 \mathrm{~h}$, respectively.
\end{abstract}

\section{Introduction}

Dried squid are popular seafood in Asian countries including China, Korea, and Japan because of their ease of availability and taste [1]. More than 10 species of squid have become the main fishing and consumer targets. Among them, jumbo squid and neon flying squid are two of the most important commercial species [2]. Typically, squid are not only consumed as fresh products but rather are processed into dried squid for storage and/or distribution. Recently, dried squid has been used as a common ingredient in many products because it contains high-quality protein and polyunsaturated fatty acids, which have increased the demand for dried squid [3]. The brown seaweed laver is also a popular marine alga in the cuisine of many countries (García Salgado et al. 2016). It is considered a medical food of the 21st century because of its high contents of minerals, vitamins, trace elements, and bioactive substances [4]. Approximately 1500 brown seaweed laver species are found in nature and several have been used in many products such as zicai (a traditional Chinese dish), nori (a popular Japanese product), and kim (a traditional Korean food ingredient) [5]. However, seaweed laver is primarily consumed in the dried, roasted, and seasoned forms; few seaweed laver snacks have been developed, limiting its consumption. Recently, consumption of snacks and side dishes for those who consume lavers has increased. Therefore, new products containing dried squid, laver, and other ingredients such as almond, seasoning, and corn syrup should be developed.

Generally, squid meat easily becomes tough and hard and splinters after drying because of its high content of insoluble myostromin, which limits the consumption of traditional dried squid by the elderly and infants [6]. Thus, it is necessary to soften dried squid to develop a new squidlaver snack (SLS). Some methods including soaking in hot water or alkaline solution have been reported for tenderizing or softening dried squid and are widely used to soften dried squid before cooking [1]. However, these methods cannot be applied to low-moisture content snacks. Thus, in this study, we used physical methods to mill dried squid and passed the squid through 7 meshes to maintain chewiness after pretreatment based on our preliminary trials. 
TABLE 1: Formulation of squid-laver snack (SLS).

\begin{tabular}{lc}
\hline Ingredient & Percent $(\%)$ \\
\hline Seasoned laver & 20.50 \\
Milled squid & 25.79 \\
Sliced almond & 12.65 \\
Dried sesame & 2.53 \\
Binding agent & 38.53 \\
\hline High-fructose corn syrup & 17.10 \\
Honey & 7.58 \\
Better & 5.06 \\
Salt & 0.51 \\
MSG & 0.1 \\
Waxy powder & 7.58 \\
\hline
\end{tabular}

Hot air-drying is the most widely used drying method for heating materials and decreases the moisture content of the materials [7]. Squid-laver snacks have low-moisture content and are a ready-to-eat snack; it is necessary to use processing steps for drying, including the use of a proper inlet air temperature and drying time. Response surface methodology (RSM) is a powerful tool for evaluating the interactive effects among different factors and determining the optimum conditions for desirable responses [8]. Fuzzy synthetic evaluation models based on fuzzy set theory have been used by a number of researchers in various environmental areas, land evaluation, and other fields [9]. Fuzzy evaluation methods process all the components according to predetermined weights and decrease the fuzziness by using the membership function; therefore, sensitivity is quite high compared with the other index evaluation techniques [10]. The aim of this study was to optimize the hot air-drying conditions to improve the quality of SLS using RSM coupled with fuzzy synthetic evaluation method.

\section{Materials and Methods}

2.1. Raw Materials. Jumbo dried squids were purchased from a local market in Gwangju, South Korea. The weight of each dried squid was approximately $90 \mathrm{~g}$. Seasoned laver was purchased from DongWang Co., Ltd. (Busan, South Korea). Dried squid and seasoned laver were stored at $-20^{\circ} \mathrm{C}$ until use.

2.2. Pretreatment of Dried Squid. Dried squid were cut into small pieces of approximately $5 \times 5 \mathrm{~cm}$ with a sharp knife and stored at $-80^{\circ} \mathrm{C}$ for approximately $5 \mathrm{~h}$ for hardening. After freezing, the dried squid were immediately milled (DH 200, Korea Trailer, Co., Ltd., Cheonan, South Korea) and passed through a 7 -mesh screen. These samples were stored at $-20^{\circ} \mathrm{C}$ until use.

2.3. Sample Preparation. The SLS were prepared using dried squid, laver, sliced almonds, and sesame following the formulation shown in Table 1. The binding agent consisted of corn syrup, starch, and other seasoning ingredients such as honey, salt, and monosodium glutamate. Milled squid, sliced

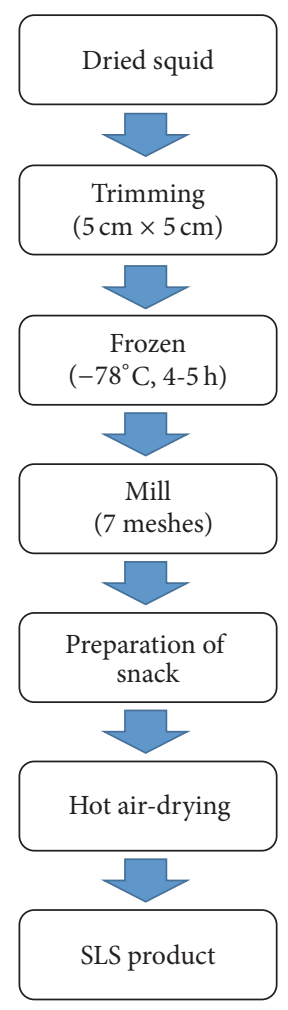

FIGURE 1: Process flowchart for the development of squid-laver.

almond, and sesame were placed between the two seaweed lavers whose surfaces had been smeared evenly with binging agent. The samples were cut into samples of $2 \times 5 \mathrm{~cm}$ before drying (Figure 1).

2.4. Experimental Design for Drying Process. The hot airdrying experiment was designed based on a two-factor central composite design of RSM (Design-Expert 8.0.6 trial version). The independent variables were $X_{1}$ (hot air temperature: $50-70^{\circ}$ ) and $X_{2}$ (drying time: $3-5 \mathrm{~h}$ ) according to preliminary trials, while the responses were moisture content $\left(Y_{1}\right)$, water activity $\left(Y_{2}\right)$, shear force $\left(Y_{3}\right), L^{*}\left(Y_{4}\right), a^{*}\left(Y_{5}\right)$, $b^{*}\left(Y_{6}\right)$, and overall acceptability $\left(Y_{7}\right)$. Table 2 shows the experimental design of the drying process.

2.5. Moisture Content. The air oven method was used to determine the moisture content of SLS [11].

2.6. Water Activity. Water activity of ground SLS was directly measured using a thermoconstanter (TH-2000, Novasina, Lachen, Switzerland) at $25^{\circ} \mathrm{C}$ as described by Kim et al. [12].

2.7. Color. The color of the SLS surface was measured using chromate (Minolta, CR-300, Osaka, Japan), and the CIE color values of $L^{*}$ (lightness), $a^{*}$ (redness), and $b^{*}$ (yellowness) were recorded.

2.8. Shear Force. The shear force of SLS was measured using a Texture Analyzer (500 N, Zwick GmbH \& Co. KG, Ulm, Germany) with a Warner-Bratzler shear blade with a guillotine probe. The probe was passed through the center of 
TABLE 2: Independent variables and their coded values used for optimization.

\begin{tabular}{lcccc}
\hline \multirow{2}{*}{ Runs } & \multicolumn{2}{c}{ Drying conditions } & \multicolumn{2}{c}{ Symbol coded } \\
& Temperature $\left({ }^{\circ} \mathrm{C}\right)$ & Time $(\mathrm{h})$ & $\times 1$ & $\times 2$ \\
\hline$(1)$ & 50 & 5 & -1 & 1 \\
$(2)$ & 60 & 4 & 0 & 0 \\
$(3)$ & 70 & 3 & 1 & -1 \\
$(4)$ & 45.86 & 4 & -1.414 & 0 \\
$(5)$ & 50 & 3 & -1 & -1 \\
$(6)$ & 74.14 & 4 & 1.414 & 0 \\
$(7)$ & 60 & 5.41 & 0 & 1.414 \\
$(8)$ & 60 & 4 & 0 & 0 \\
$(9)$ & 60 & 4 & 0 & 0 \\
$(10)$ & 60 & 2.59 & 0 & -1.414 \\
$(11)$ & 70 & 5 & 1 & 1 \\
$(12)$ & 60 & 4 & 0 & 0 \\
$(13)$ & 60 & 4 & 0 & 0 \\
\hline
\end{tabular}

the SLS and the load cell, pretest speed, and test speed were $5 \mathrm{~g}, 1.0 \mathrm{~mm} / \mathrm{s}$, and $0.5 \mathrm{~mm} / \mathrm{s}$, respectively $[13,14]$. The shear force was the maximum force required to break the SLS.

2.9. Overall Acceptability. Sensory evaluation for SLS was performed by 15 panelists as described by Norajit et al. [15] with some modifications. The panelists were students of Food Science and Technology, Chonnam National University, and consisted of $47 \%$ males and $53 \%$ females. The overall sensory characteristics were evaluated based on a 7-point scale ( 7 for excellent, 4 for good, and 1 for very poor).

2.10. Fuzzy Synthetic Evaluation. Fuzzy synthetic evaluation is commonly used technique to solve problems with constraints involving nonlinear functions. The method aims to solve sequences of sample problems whose solutions coverage to the solutions of the original problems [16]. To evaluate the contributions of each response including moisture content, water activity, color, shear force, and overall acceptability, the synthetic evaluation $(S)$ and membership value $(M)$ were used. The $M$ values of overall acceptability, $L^{*}$, were calculated using (1), while those of moisture content, water activity, and $a^{*}$ and $b^{*}$ were calculated using (2).

$$
\begin{aligned}
& M_{i j}=\frac{C_{i j}-C_{\min , j}}{C_{\max , j}-C_{\min , j}}, \\
& M_{i j}=\frac{C_{\max , j}-C_{i j}}{C_{\max , j}-C_{\min , j}},
\end{aligned}
$$

where $C_{\max }$ and $C_{\min }$ are the maximum and minimum values of the response variables, $i$ is the number of response variables according to the order of moisture content, water activity, overall acceptability, shear force, $L^{*}, a^{*}$, and $b^{*}$, and $j$ is the number of experimental runs ranging from 1 to 13 .

Of those responses, moisture content was set as the most important factor and water activity as the second most important factor. By considering SLS as a ready-toeat snack, overall acceptability was considered as the third most important factor. The shear force was set as the fourth most important factor, followed by color $\left(L^{*}, a^{*}\right.$, and $\left.b^{*}\right)$. The sum of the weights of the coefficients should be 1 . Thus, the weight coefficient $(\lambda)$ of moisture content, water activity, overall acceptability, shear force, $L^{*}, a^{*}$, and $b^{*}$ were 0.30 , $0.25,0.20,0.10,0.05,0.05$, and 0.05 , respectively $[17,18]$. A synthetic evaluation index $(S)$ was calculated using

$$
S_{j}=\sum_{i=1}^{7} \lambda_{i} M_{i j}
$$

where $S$ is the synthetic evaluation index, $M$ is the membership value, $i$ is the number of response variables according to the order of moisture content, water activity, overall acceptability, shear force, $L^{*}, a^{*}$, and $b^{*}$, and $j$ is the number of experimental runs ranging from 1 to 13 .

2.11. Statistical Analysis. All measurements were conducted in triplicate. The experimental data were statistically analyzed using Design-Expert 8.0.6 software (state-Ease, Inc., Minneapolis MN, USA). A second-order polynomial model was used to predict the response variables based on multiple linear regression analysis. The equation is shown below:

$$
Y=b_{0}+b_{1} X_{1}+b_{2} X_{2}+b_{1}^{2} X_{1}^{2}+b_{2}^{2} X_{2}^{2}+b_{1} b_{2} X_{1} X_{2}
$$

where $Y$ is the predicted dependent variable, $b_{0}$ is a constant that fixed the response at the central point of the experiment, and $b_{1}, b_{2}, b_{1}{ }^{2}$, and $b_{2}^{2}$ are the linear, quadratic, and interaction coefficients, respectively. $X_{1}$ and $X_{2}$ are independent variables.

Regression analysis of the models represented by (4) and significant terms were evaluated for each response by multiple regression and variance (ANOVA) analysis, respectively. Moreover, the adequacy of the models was examined using model analysis, lack-of fit test, pure error, and $R^{2}$ analysis $[19,20]$.

\section{Results and Discussion}

3.1. Selection of Independent Variable Levels. In this study, the drying temperature $\left(50-70^{\circ} \mathrm{C}\right)$ and drying time $(3-5 \mathrm{~h})$ were chosen for the hot air-drying process based on our preliminary trials. If the air temperature was too high and drying time was too long, hardening occurred and a casing formed. This may be because moisture was removed from the surface of foods being dried more rapidly than water could diffuse from the moist interior of the food particle [21]. A low drying temperature and short drying time could not effectively remove the moisture to reach the level of moisture needed for an SLS.

The results of response variables, including moisture content, water activity, color $\left(L^{*}, a^{*}, b^{*}\right)$, shear force, and overall acceptance under different drying conditions are reported in Table 3 . The minimum $R^{2}$ was 0.8 , which indicated that the data fit the statistical model [22]. As shown in Table 4, a high correlation coefficient explained 
TABLE 3: Experimental values of response variables for response surface design.

\begin{tabular}{|c|c|c|c|c|c|c|c|}
\hline Runs & Water content (\%) & Water activity & $L^{*}$ & $a^{*}$ & $b^{*}$ & Shear force & Overall acceptability \\
\hline (1) & 6.65 & 0.116 & 31.12 & -0.39 & 6.81 & 85.32 & 3.67 \\
\hline (2) & 6.63 & 0.112 & 30.33 & -0.3 & 6.22 & 107.50 & 3.87 \\
\hline (3) & 5.97 & 0.093 & 31.59 & -0.37 & 7.49 & 97.49 & 4.15 \\
\hline (4) & 9.07 & 0.135 & 31.04 & -0.33 & 6.97 & 91.86 & 3.66 \\
\hline (5) & 8.91 & 0.136 & 30.76 & -0.30 & 7.07 & 78.85 & 3.75 \\
\hline (6) & 4.76 & 0.056 & 31.07 & -0.37 & 7.38 & 98.74 & 3.67 \\
\hline (7) & 6.45 & 0.071 & 31.24 & -0.34 & 6.96 & 123.80 & 3.86 \\
\hline (8) & 6.74 & 0.108 & 30.17 & -0.33 & 6.70 & 95.88 & 4.06 \\
\hline (9) & 6.60 & 0.110 & 29.09 & -0.31 & 6.05 & 98.74 & 3.96 \\
\hline (10) & 6.74 & 0.122 & 31.16 & -0.32 & 7.35 & 111.34 & 3.54 \\
\hline (11) & 5.55 & 0.057 & 31.82 & -0.32 & 7.55 & 125.34 & 3.66 \\
\hline (12) & 6.6 & 0.111 & 29.44 & -0.34 & 6.76 & 101.56 & 4.13 \\
\hline (13) & 6.6 & 0.11 & 30.61 & -0.38 & 6.47 & 100.64 & 4.18 \\
\hline
\end{tabular}
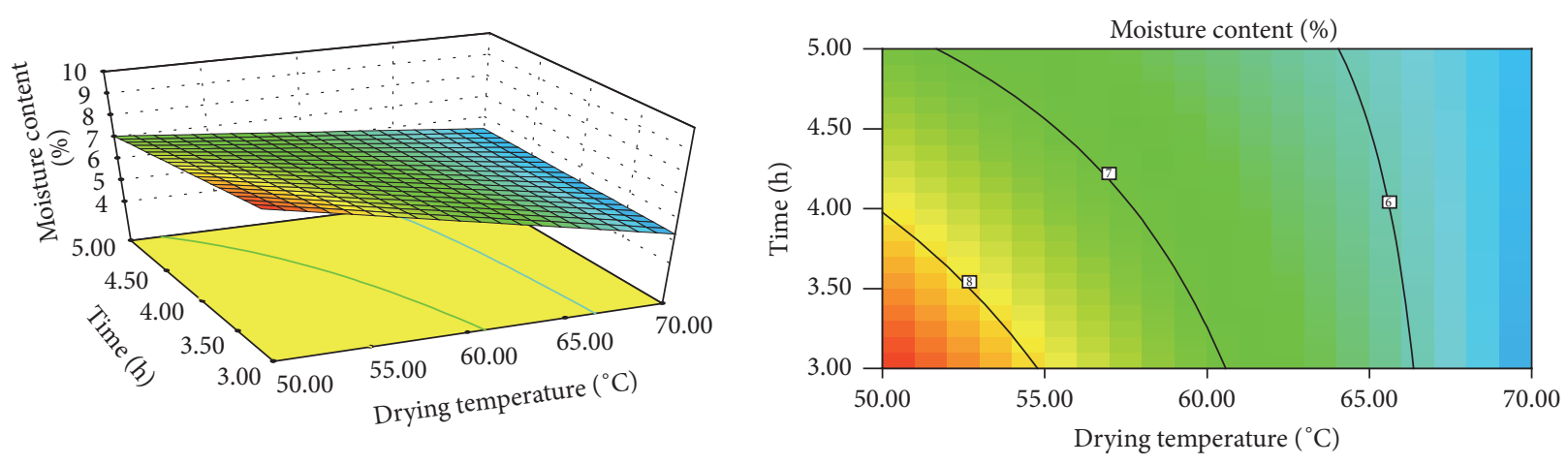

FIGURE 2: 3D response surface and contour plots for the effect of drying temperature and time on moisture content of SLS.

the goodness of fit of the experimental data for the response surface models of moisture content, water activity, $b$ value, shear force, and overall acceptability. The 3D surface graphs for these responses were developed as a function of the two independent variables according to the significance of the responses. Multiple responses were optimized using a synthetic evaluation method [17].

3.2. Moisture Content. The final moisture content of the dried SLS was $4.76-9.07 \%$. The minimum moisture content $(4.76 \%)$ was found at a drying temperature of $74.14^{\circ} \mathrm{C}$ and drying time of $4 \mathrm{~h}$, while the maximum moisture content $(9.07 \%)$ was recorded at a drying temperature of $45.86^{\circ} \mathrm{C}$ and drying time of $4 \mathrm{~h}$ (Table 3). The 3D plot (Figure 2) presents the effect of drying conditions (drying temperature and drying time) on moisture content. Based on the results of the response surface model, drying temperature and time significantly affected the moisture content in a linear manner. In addition, an interaction term for drying temperature and time was also observed. The following regression equation describes the effect of the process variables on the moisture content of SLS:

$$
\begin{aligned}
& \text { Moisture content }\left(Y_{1}\right) \\
& \qquad=6.71-1.27 X_{1}-0.39 X_{2}+0.46 X_{1} X_{2} .
\end{aligned}
$$

The negative coefficients of the first-order terms of drying temperature and time indicated that moisture content decreased when these variables were increased. Our results were in accordance with those of a previous study by Patil et al. [23], who reported that the moisture content of encapsulated pandan extract was decreased following firstorder regression by increasing the inlet air temperature during spray-drying. In contrast, Nath and Chattopadhyay [20] observed a first-order regression and quadratic terms for drying temperature and time on the moisture content during oven roasting of potato-soy snack. The minor difference from our results may be related to the variety of the samples and time ranges used for drying. In our experiment, both the drying temperature and time for hot air-drying decreased the moisture content of SLS to a first-order regression.

3.3. Water Activity. The amount of available water in a dried product may directly and positively influence microbiological stability. It has been reported that microorganisms grow best between water activity (aw) values $0.98-0.99$, and most microbes cease growing at aw $<0.90$. Some fungi stop growing at aw value as low as 0.62 [24]. Thus, water activity is the key parameter affecting microbiological spoilage. In our study, the aw of SLS ranged from 0.056 to 0.136 after drying, indicating that the SLS was in a stable state (Table 3). 


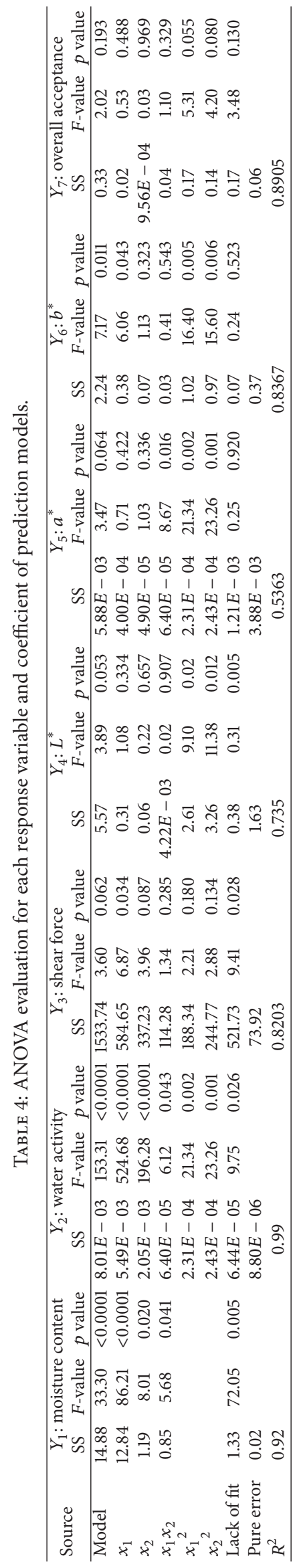



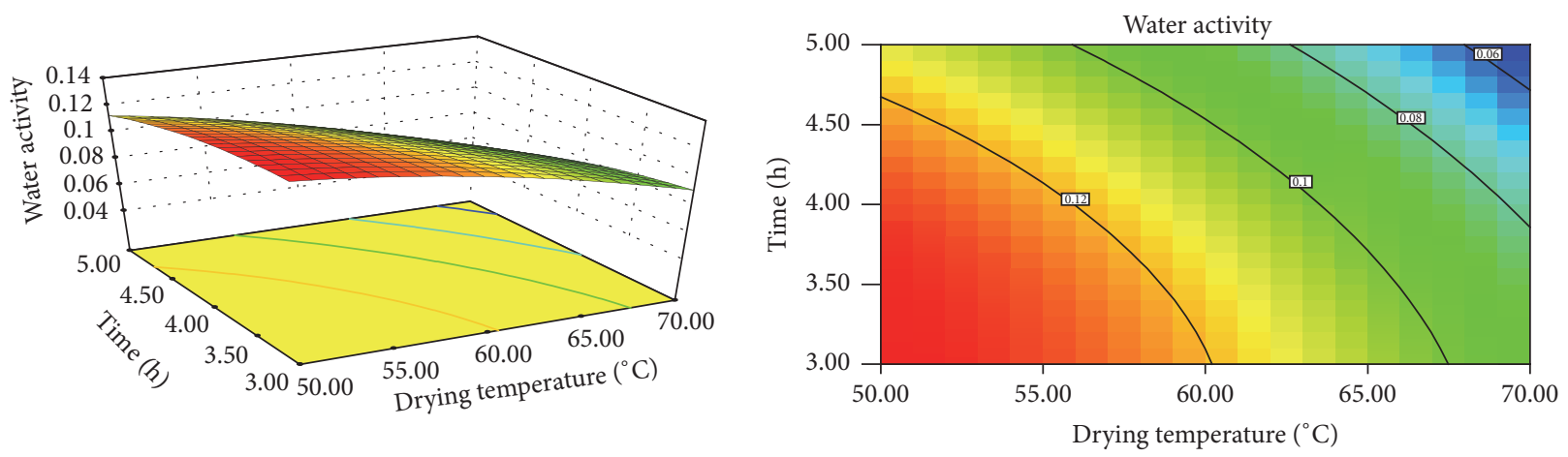

FIGURE 3: 3D response surface and contour plots for the effect of drying temperature and time on water activity of SLS.
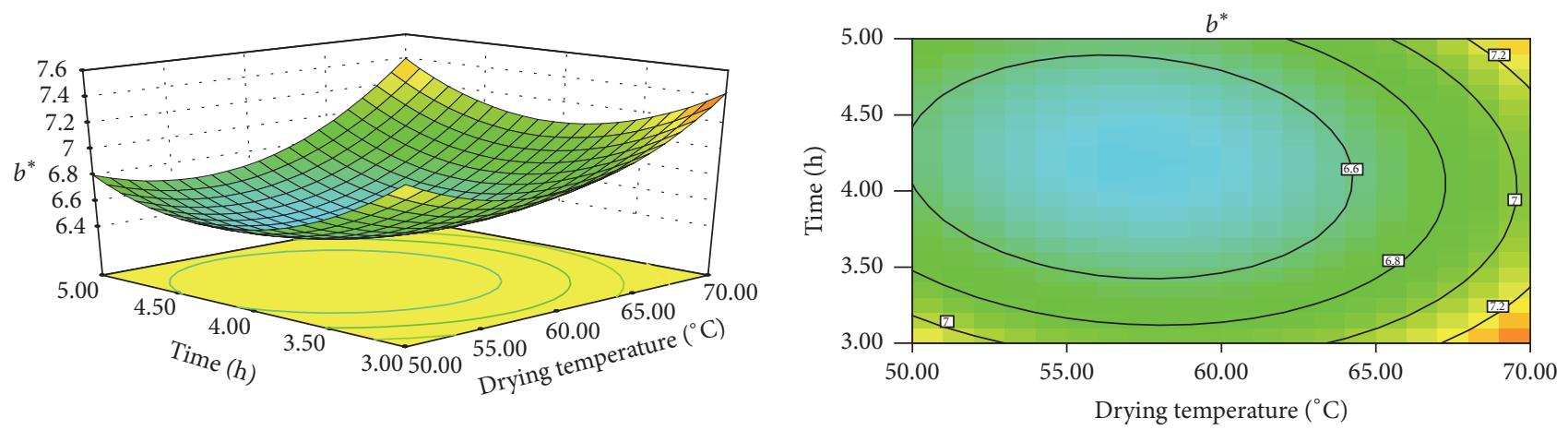

FIGURE 4: 3D response surface and contour plots for the effect of drying temperature and time on $b^{*}$ value of SLS.

The lowest aw value was observed at the lowest moisture content, which may be because of the correlation between these parameters. Based on the results of the aw model and $3 \mathrm{D}$ plot, the drying temperature and drying time showed significant linear effects, as well as an interaction term effect for drying temperature and drying time on the aw (Figure 3). The regression equation describing the effect of drying temperature and time on the aw of SLS in terms of measured levels for the variables was as follows:

$$
\begin{aligned}
\text { Water activity }\left(Y_{2}\right)= & 0.11-0.026 X_{1}-0.016 X_{2} \\
& -0.004 X_{1} X_{2} .
\end{aligned}
$$

The linear and quadratic effects were negative, indicating that the water activity of SLS decreased with increasing drying temperatures and times (6). Our results were similar to those of a previous study by Šumić et al. [25] who reported that drying temperature and time significantly affected the water activity of red currants during vacuum-drying following a first-order effect model. In their study, quadratic effects were also observed but were not obvious. This may be explained by the different time ranges chosen for the drying process.

3.4. Color. Color is an important attribute of SLS and contributes to consumer preference. Generally, color is produced by chemical reactions such as the Maillard reaction, which occurs between free amino acids and reduced sugar. In our experiment, the color parameters of SLS including $L^{*}, a^{*}$, and $b^{*}$ values were measured during the hot air-drying process.
Low correlation coefficients were observed for $L^{*}$ and $a^{*}$ value ( 0.7350 and 0.5362 , resp.) (Table 4$)$. Multiple regression analysis was used to evaluate the $b^{*}$ value, which fit well the experimental data. The model for the response value was expressed using the following quadratic polynomial equation:

$$
\begin{aligned}
b^{*} \text { value }\left(Y_{6}\right)= & 6.44+0.22 X_{1}-0.094 X_{2} \\
& +0.08 X_{1} X_{2}+0.38 X_{1}^{2}+0.37 X_{2}^{2} .
\end{aligned}
$$

Based on (7), positive quadratic effects for drying temperature and time were observed for the $b^{*}$ value. Additionally, a negative linear but insignificant effect of drying time was observed. The $b^{*}$ value of SLS ranged from 6.05 to 7.55 and minimum $b^{*}$ value (6.05) was observed at a drying temperature of $60^{\circ} \mathrm{C}$ and drying time of $4 \mathrm{~h}$. The maximum $b^{*}$ value (7.55) was found at a drying temperature of $70^{\circ} \mathrm{C}$ and drying time of $5 \mathrm{~h}$. Based on the results of the 3D plot (Figure 4), the $b^{*}$ value slightly decreased at temperatures $50-60^{\circ} \mathrm{C}$, followed by a slight increase with increasing temperature. The $b^{*}$ value decreased possibly because the pigment in seaweed laver was destroyed at temperatures of $50-60^{\circ} \mathrm{C}$, while a caramelization reaction occurred when the sample was dried at a high temperature, causing an increase in the $b^{*}$ value [26]. Similar results were reported by Rodriguez et al. [27] who found that the color parameter $b^{*}$ of laver decreased significantly after drying and the yellow color was changed to blue-violet.

3.5. Shear Force. Shear force is an important parameter that markedly affects the quality of ready-to-eat snack products 

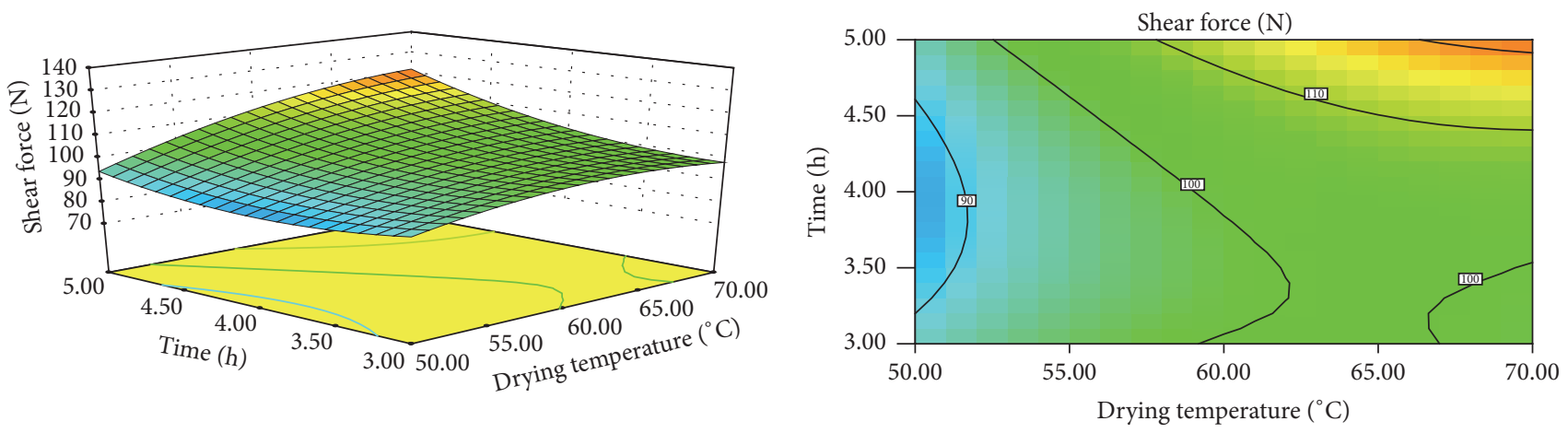

FIGURE 5: 3D response surface and contour plots for the effect of drying temperature and time on shear force value of SLS.
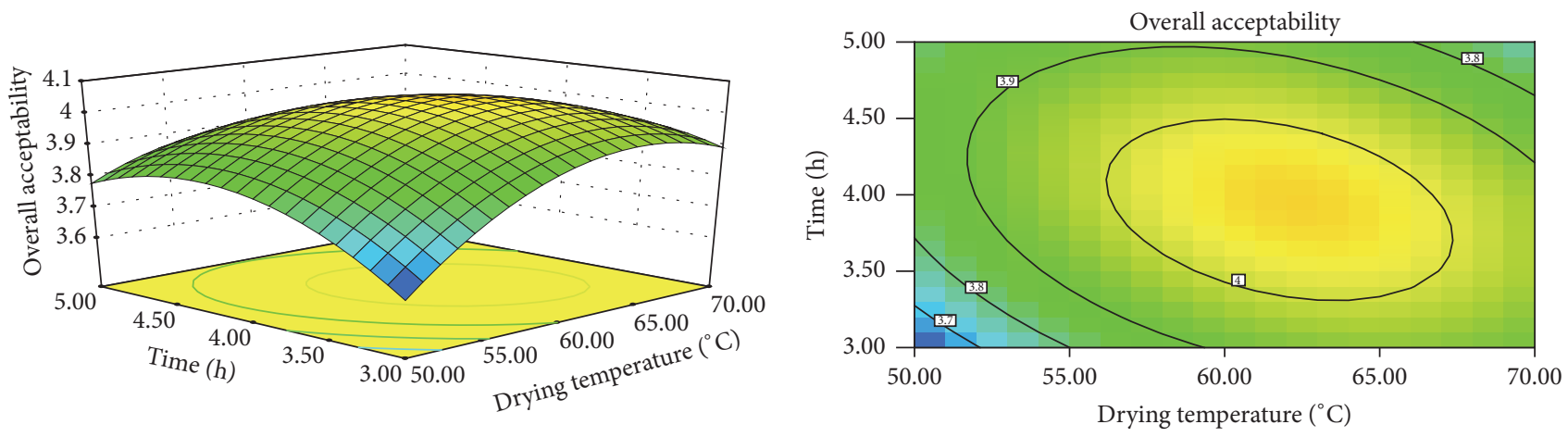

FIGURE 6: 3D response surface and contour plots for the effect of drying temperature and time on overall acceptability value of SLS.

[28]. In our experiment, the shear force value of SLS ranged from 85.32 to $125.34 \mathrm{~N}$. The minimum and maximum shear force values were observed at a drying temperature of $50^{\circ} \mathrm{C}$ and time of $5 \mathrm{~h}$ and drying temperature of $70^{\circ} \mathrm{C}$ and time of $5 \mathrm{~h}$, respectively (Table 3 ). The analysis of variance results for the response surface model of shear force showed that the drying temperature and drying time had a significant linear effect on the shear force of SLS $(p<0.05)$. A quadratic and interaction term for drying temperature and time affected the shear force, but not significantly $(p>0.05)$. The quadratic polynomial equation for shear force is as follows:

$$
\begin{aligned}
\text { Shear force }\left(Y_{3}\right)= & 100.86+8.55 X_{1}+6.49 X_{2} \\
& +5.34 X_{1} X_{2}-5.20 X_{1}{ }^{2} \\
& +5.93 X_{2}{ }^{2} .
\end{aligned}
$$

The positive coefficients of the first-order terms of drying temperature and time indicated that the shear force increased as these variables increased. A negative quadratic effect for drying temperature was also observed. Based on (8) the drying temperature showed a greater effect than drying time on shear force because the response surface of shear force showed a greater change when drying temperature was varied. In addition, Figure 5 shows the shear force of SLS as a function of drying temperature and time. The shear force was significantly increased with increasing drying temperature and time. Similar results were observed in a previous study by Kumar et al. [29] who reported that the shear force of dried okra increased with increasing drying temperature. NketsiaTabiri and Sefa-Dedeh [30] also point out that the shear force of salted fish depended on the drying temperature and time. A positive linear and quadratic effect of drying time on the shear force of raw noodle was also reported by Khare et al. [31].

3.6. Overall Acceptance. Overall acceptability values of SLS during drying with different combinations of drying temperature and time are presented in Table 2. The maximum overall acceptability value was 4.18 at a drying temperature of $60^{\circ} \mathrm{C}$ and time of $4 \mathrm{~h}$, while the minimum was 3.54 at a drying temperature of $60^{\circ} \mathrm{C}$ and time of $2.59 \mathrm{~h}$, respectively (Table 3). Based on the results of ANOVA for overall acceptability, a significant quadratic model effect of drying temperature and time on the overall acceptability was observed $(p<0.05)$, while the linear and interaction terms of drying parameters were not obvious. The 3D plot showing the effect of drying temperature and time on overall acceptability is shown in Figure 6. During the first $4.5 \mathrm{~h}$ drying process, the overall acceptability value increased but decreased as the drying process was continued, which may be explained by increase in shear force. In addition, the higher temperature hardened the SLS and created a casing on it. The final equation in terms of coded factors is shown as

$$
\begin{aligned}
& \text { Overall acceptability }\left(Y_{7}\right) \\
& \begin{aligned}
= & 4.04+0.047 X_{1}-0.011 X_{2}-0.095 X_{1} X_{2} \\
& -0.16 X_{1}^{2}-0.14 X_{2}^{2} .
\end{aligned}
\end{aligned}
$$


TABLE 5: Membership value of each response variable and synthetic evaluation index $(S)$ for response surface design.

\begin{tabular}{lccccccccc}
\hline Runs & Moisture content & Water activity & Overall acceptability & Shear force & $L^{*}$ & $a^{*}$ & $b^{*}$ & \multicolumn{1}{c}{$S$} \\
\hline$(1)$ & 0.5615 & 0.25 & 0.2031 & 1 & 0.7436 & 1 & 0.4933 & 0.4834 \\
$(2)$ & 0.5661 & 0.3 & 0.5156 & 0.4458 & 0.4542 & 0 & 0.8867 & 0.4596 \\
$(3)$ & 0.7193 & 0.5375 & 0.9062 & 0.6959 & 0.9158 & 0.7778 & 0.04 & 0.6877 \\
$(4)$ & 0 & 0.0125 & 0.1875 & 0.8365 & 0.7143 & 0.3333 & 0.3867 & 0.1960 \\
$(5)$ & 0.0371 & 0 & 0.3281 & 1.1617 & 0.6117 & 0 & 0.32 & 0.2400 \\
$(6)$ & 1 & 1 & 0.2031 & 0.6647 & 0.7252 & 0.7778 & 0.1133 & 0.7379 \\
$(7)$ & 0.6079 & 0.8125 & 0.5 & 0.0385 & 0.7875 & 0.4444 & 0.3933 & 0.5706 \\
$(8)$ & 0.5406 & 0.35 & 0.8125 & 0.7361 & 0.3956 & 0.3333 & 0.5667 & 0.5506 \\
$(9)$ & 0.5731 & 0.325 & 0.6563 & 0.6647 & 0 & 0.1111 & 1 \\
$(10)$ & 0.5406 & 0.175 & 0 & 0.3498 & 0.7582 & 0.2222 & 0.1333 & 0.2966 \\
$(11)$ & 0.8167 & 0.9875 & 0.1875 & 0 & 1 & 0.2222 & 0 & 0.5905 \\
$(12)$ & 0.5731 & 0.3125 & 0.9219 & 0.5942 & 0.1282 & 0.4444 & 0.5267 & 0.5488 \\
$(13)$ & 0.5731 & 0.325 & 1 & 0.6172 & 0.5568 & 0.8889 & 0.72 & 0.6232 \\
\hline
\end{tabular}

TABLE 6: ANOVA evaluation for synthetic evaluation index $(S)$ and coefficient of prediction model.

\begin{tabular}{lccc}
\hline Source & SS & $F$-value & $p$ value \\
\hline Model & 0.28 & 18.62 & 0.0003 \\
$x_{1}$ & 0.22 & 43.09 & 0.0001 \\
$x_{2}$ & 0.036 & 7.04 & 0.0263 \\
$x_{1} x_{2}$ & 0.029 & 5.74 & 0.0402 \\
Lack of fit & 0.031 & 1.69 & 0.3165 \\
Pure error & 0.015 & & \\
$R^{2}$ & 0.8613 & & \\
\hline
\end{tabular}

The negative coefficients for drying temperature and time indicated that overall acceptability values increased up to a limit but decreased as the drying process continued. Nath and Chattopadhyay [20] reported a quadratic terms effect of temperature and time on the overall acceptability values of potato-soy snack, and large increases in these variables resulted in decreased overall acceptability values.

3.7. Synthetic Evaluation. In our study, although the $L^{*}$ and $a^{*}$ values showed low correlation coefficients in the model $(<0.80)$, they affected the weight factors of other parameters and synthetic evaluation index value. To comprehensively investigate the efficiency of the quality of SLS, $L^{*}$ and $a^{*}$ values were also included in the synthetic evaluation index. Table 5 shows the membership value of each response variable and synthetic evaluation index $(S)$. The $S$ value for the response surface design ranged from 0.1960 to 0.7379 ; the minimum $S$ value was recorded at a drying temperature of $45.86^{\circ} \mathrm{C}$ and drying time of $4 \mathrm{~h}$, while the maximum value was found at a drying temperature of $74.14^{\circ} \mathrm{C}$ and drying time of $4 \mathrm{~h}$.

ANOVA results for the $S$ value are listed in Table 6 . A good coefficient of determination $\left(R^{2}=0.8613\right)$ was obtained. Drying temperature and time showed significant linear effects on the $S$ value. In addition, interaction effects for drying temperature and time were observed. The predicted model obtained for $S$ value was as follows:

$$
S=0.50+0.17 X_{1}+0.067 X_{2}-0.085 X_{1} X_{2} .
$$

As shown by (10), the drying temperature had greater effects on the $S$ value than the drying time because of the higher coefficient estimate values for drying temperature. The 3D plot shows that the $S$ value increased with increasing drying temperature and time (Figure 7). Similar results were observed by Wang et al. [17], who found that the drying temperature had linear effects on the synthetic evaluation index of okara during the drying process.

3.8. Optimization of Hot Air-Drying Parameters. The numerical analysis and graphic optimization techniques of the Design-Expert software were used for the simultaneous optimization of the multiple responses. All of the independent variables were kept within range, while the described targets for each response are presented in Table 7. Based on the desirability of the solution generated by the software, one optimal condition was obtained, which was a drying temperature of $70^{\circ} \mathrm{C}$ and drying time of $3 \mathrm{~h}$ with a predicted $S$ value of 0.6830 . The moisture content, water activity, overall acceptability, shear force, $L^{*}, a^{*}$, and $b^{*}$ of SLS samples dried under the optimized conditions are presented in Table 7. According to (10) the actual value of $S$ was 0.6877 , which was close to the predicted value.

\section{Conclusion}

An SLS prepared with dried squid, laver, and almond was developed using a hot air-drying process. Drying temperature and drying time significantly affected the response values including moisture content, water activity, color, shear force, and overall acceptability. The drying temperature had a stronger effect than the drying time on synthetic evaluation. The optimum conditions for hot air-drying of SLS were identified as $70^{\circ} \mathrm{C}$ for $3 \mathrm{~h}$. 

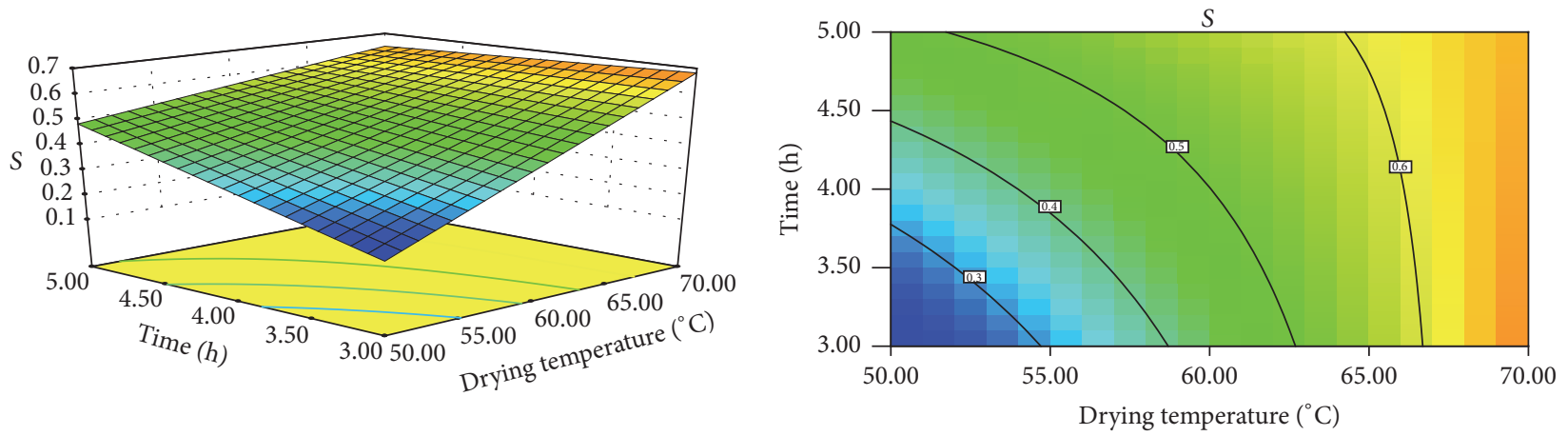

FIGURE 7: 3D response surface and contour plots for the effect of drying temperature and time on synthetic evaluation index (S) of SLS.

TABLE 7: Simultaneously optimized hot air drying conditions with target and experimental values of investigated responses.

\begin{tabular}{lcc}
\hline Responses & Target & Experiment values \\
\hline Moisture content (\%) & Minimized & 5.79 \\
Water activity & Minimized & 0.09 \\
$L^{*}$ & Maximized & 31.59 \\
$a^{*}$ & Minimized & -0.37 \\
$b^{*}$ & Minimized & 7.49 \\
Shear force (N) & Minimized & 97.49 \\
Overall acceptability & Maximized & 4.15 \\
$S$ & Maximized & 0.69 \\
\hline
\end{tabular}

\section{Additional Points}

Practical Application. Recently, consumption of snacks and side dishes from seafood has increased; thus, new products containing dried squid, laver, and other ingredients should be developed. The data from this study reveal a practical application worthy of further study in food industries. It would provide valuable information to develop seafood snacks by hot air-drying method.

\section{Conflicts of Interest}

The authors declare that there are no conflicts of interest regarding the publication of this paper.

\section{References}

[1] S. Benjakul, W. Visessanguan, M. Tanaka, S. Ishizaki, A. Taluengphol, and U. Chichanan, "Physicochemical and textural properties of dried squid as affected by alkaline treatments," Journal of the Science of Food and Agriculture, vol. 80, no. 14, pp. 2142-2148, 2000.

[2] X. J. Chena, B. L. Liua, and Y. Chen, "Jumbo squid and neon flying squid were two most important commercial species," Fish Res, vol. 89, no. 3, pp. 211-221, 2008.

[3] Y. Zhang, G. Wang, Y. Jin, Y. Deng, and Y. Zhao, "Effects of high hydrostatic pressure processing on purine, taurine, cholesterol, antioxidant micronutrients and antioxidant activity of squid (Todarodes pacificus) muscles," Food Control, vol. 60, pp. 189195, 2016.
[4] S. I. Khan and S. B. Satam, "Seaweed mariculture: scope and potential: in India," Aquaculture Asia, vol. 8, no. 4, pp. 426-429, 2003.

[5] E.-S. Hwang, K.-N. Ki, and H.-Y. Chung, "Proximate composition, amino acid, mineral, and heavy metal content of dried laver," Preventive Nutrition and Food Science, vol. 18, no. 2, pp. 139-144, 2013.

[6] A. Thanonkaew, S. Benjakul, and W. Visessanguan, "Chemical composition and thermal property of cuttlefish (Sepia pharaonis) muscle," Journal of Food Composition and Analysis, vol. 19, no. 2-3, pp. 127-133, 2006.

[7] Q. Wang, Z. Gu, J. Bai, J. Liu, and H. Liu, "Comparative Study of the Characteristics of Oil Shale with Hot Air Drying and Microwave Drying," Energy Procedia, vol. 17, pp. 884-891, 2012.

[8] D. Bas and I. H. Boyaci, "Modeling and optimization I: usability of response surface methodology," Journal of Food Engineering, vol. 78, no. 3, pp. 836-845, 2007.

[9] J.-H. Wang, X.-G. Lu, M. Jiang, X.-Y. Li, and J.-H. Tian, "Fuzzy Synthetic Evaluation of Wetland Soil Quality Degradation: A Case Study on the Sanjiang Plain, Northeast China," Pedosphere, vol. 19, no. 6, pp. 756-764, 2009.

[10] G. Onkal-Engin, I. Demir, and H. Hiz, "Assessment of urban air quality in Istanbul using fuzzy synthetic evaluation," Atmospheric Environment, vol. 38, no. 23, pp. 3809-3815, 2004.

[11] Association of Official Analytical Chemists (AOAC), Official Methods of Analysis, S. Williams, Ed., Association of Official Analytical Chemists, 15th edition, 2005.

[12] Y. Kim, S. Lee, M. Kim et al., "Physicochemical and organoleptic qualities of sliced-dried persimmons as affected by drying methods," Korean Journal of Food Science and Technology, vol. 41, no. 1, pp. 64-68, 2009.

[13] A. M. Paula and A. C. Conti-Silva, "Texture profile and correlation between sensory and instrumental analyses on extruded snacks," Journal of Food Engineering, vol. 121, no. 1, pp. 9-14, 2014.

[14] Y. Deng, Y. Luo, Y. Wang et al., "Drying-induced protein and microstructure damages of squid fillets affected moisture distribution and rehydration ability during rehydration," Journal of Food Engineering, vol. 123, pp. 23-31, 2014.

[15] K. Norajit, B.-J. Gu, and G.-H. Ryu, "Effects of the addition of hemp powder on the physicochemical properties and energy bar qualities of extruded rice," Food Chemistry, vol. 129, no. 4, pp. 1919-1925, 2011.

[16] M. Arsenović, L. Pezo, and Z. Radojevic, "Response surface method as a tool for heavy clay firing process optimization: 
Roofing tiles," Processing and Application of Ceramics, vol. 6, no. 4, pp. 209-214, 2012.

[17] G. Wang, Y. Deng, X. Xu et al., "Optimization of air jet impingement drying of okara using response surface methodology," Food Control, vol. 59, pp. 743-749, 2016.

[18] L. Zhang, W. Zhang, Z. Lü, and Z. Wang, "Optimization of intermittent microwave drying technology for lees by response surface methodology," Transactions of the CSAE, vol. 27, no. 3, pp. 369-374, 2011.

[19] J. Lee, L. Ye, W. O. Landen Jr., and R. R. Eitenmiller, "Optimization of an Extraction Procedure for the Quantification of Vitamin E in Tomato and Broccoli using Response Surface Methodology," Journal of Food Composition and Analysis, vol. 13, no. 1, pp. 45-57, 2000.

[20] A. Nath and P. K. Chattopadhyay, "Optimization of oven toasting for improving crispness and other quality attributes of ready to eat potato-soy snack using response surface methodology," Journal of Food Engineering, vol. 80, no. 4, pp. 1282-1292, 2007.

[21] I. S. Afolabi, "Moisture migration and bulk nutrients interaction in a drying food systems: a review," Journal of Food and Nutrition Sciences, vol. 05, no. 8, pp. 692-714, 2014.

[22] A. M. Joglekar and A. T. May, "Product excellence through design of experiments," Cereal Food World, vol. 32, pp. 857-868, 1987.

[23] V. Patil, A. K. Chauhan, and R. P. Singh, "Optimization of the spray-drying process for developing guava powder using response surface methodology," Powder Technology, vol. 253, pp. 230-236, 2014.

[24] M. Raimbault, "General and microbiological aspects of solid substrate fermentation," Electronic Journal of Biotechnology, vol. 1, no. 3, pp. 114-140, 1998.

[25] Z. Šumić, A. Vakula, A. Tepić, J. Čakarević, J. Vitas, and B. Pavlić, "Modeling and optimization of red currants vacuum drying process by response surface methodology (RSM)," Food Chemistry, vol. 203, pp. 465-475, 2016.

[26] M. L. Martínez, M. A. Marín, and P. D. Ribotta, “Optimization of soybean heat-treating using a fluidized bed dryer," Journal of Food Science and Technology, vol. 50, no. 6, pp. 1144-1150, 2013.

[27] T. V. Rodriguez, A. M. Rojas, C. A. Campos, and L. N. Gerschenson, "Effect of osmotic dehydration on the quality of air-dried Porphyra," LWT - Food Sci Technol, vol. 36, no. 4, pp. 415-422, 2003.

[28] M. C. Bourne, Food Texture And Viscosity: Concept And Measurement, State Agricultural Experiment Station and Institute of Food Science. Cornell University, Geneva, Switzerland, 2nd edition, 2002.

[29] D. Kumar, S. Prasad, and G. S. Murthy, "Optimization of microwave-assisted hot air drying conditions of okra using response surface methodology," Journal of Food Science and Technology, vol. 51, no. 2, pp. 221-232, 2014.

[30] J. Nketsia-Tabiri and S. Sefa-Dedeh, "Optimization of process conditions and quality of salted dried tilapia (Oreochromis niloticus) using response surface methodology," Journal of the Science of Food and Agriculture, vol. 69, no. 1, pp. 117-127, 1995.

[31] A. K. Khare, A. K. Biswas, S. Balasubramanium, M. K. Chatli, and J. Sahoo, "Optimization of meat level and processing conditions for development of chicken meat noodles using response surface methodology," Journal of Food Science and Technology, vol. 52, no. 6, pp. 3719-3729, 2015. 

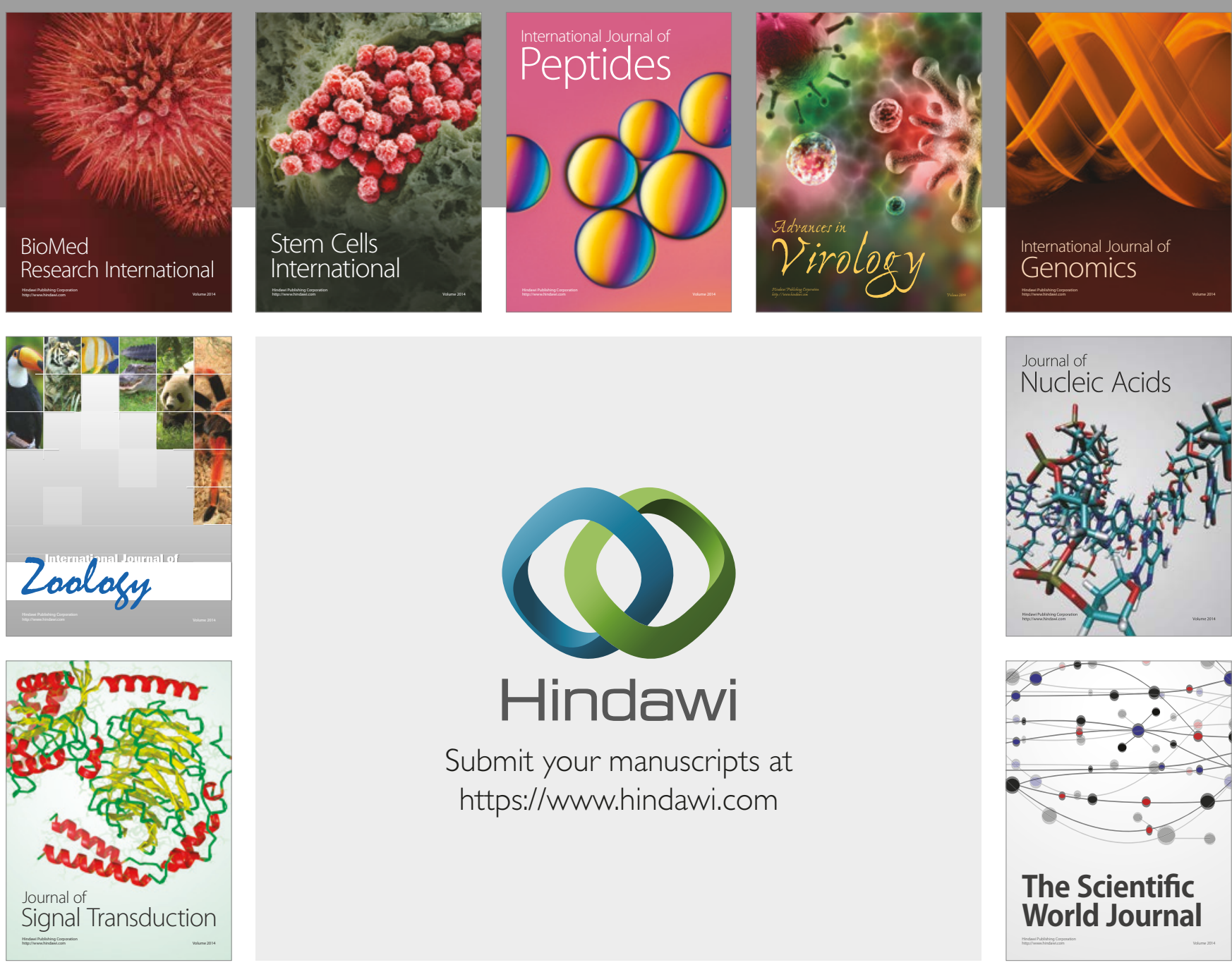

Submit your manuscripts at

https://www.hindawi.com
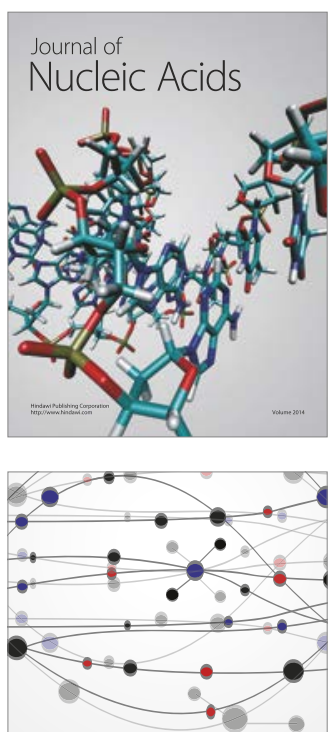

The Scientific World Journal

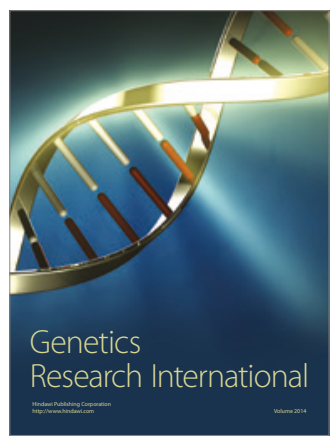

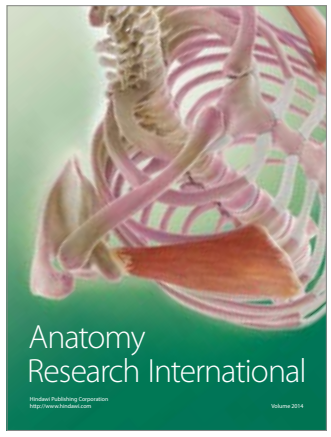

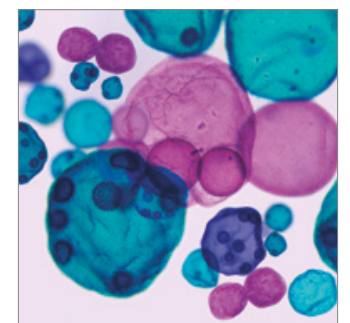

International Journal of Microbiology
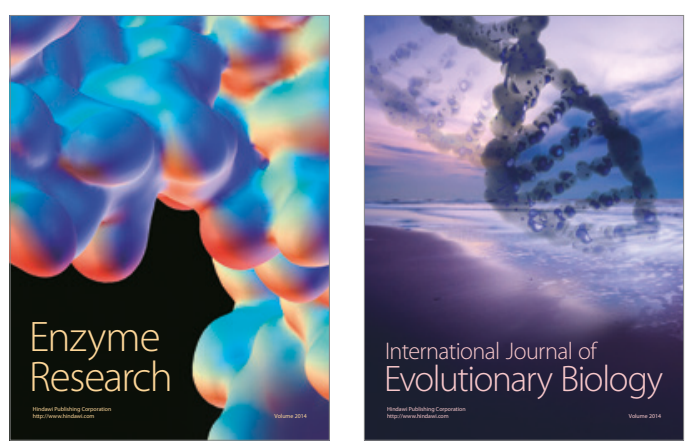
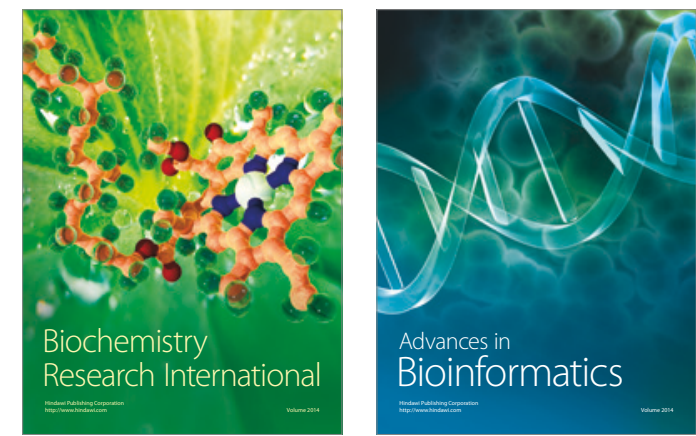

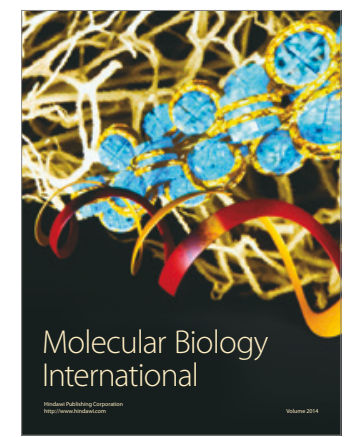

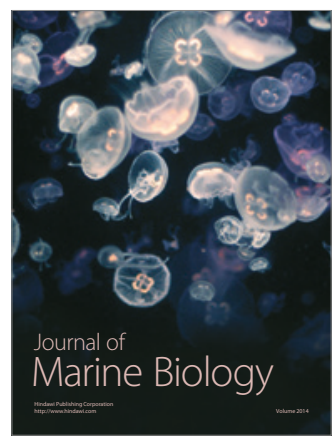

